\title{
Human Papillomavirus (HPV) Detection in Keratotic Variants of Oral Lichen Planus: Negative Results in a Preliminary Open Study
}

\author{
V Panzarella ${ }^{1}$, G Capra $^{2}$, L Giovannelli ${ }^{3}$, G Campisi ${ }^{1}$ \\ ${ }^{1}$ Dpt. of Surgical, Oncological and Oral Sciences, University of Palermo, Palermo, Italy \\ ${ }^{2}$ Dpt. of of Sciences for Health Promotion and Mother-Child Care "G. D’Alessandro"; \\ University of Palermo, Italy \\ ${ }^{3}$ Dpt. of International Relations and Health Research, Azienda Opedaliera Universitaria Policlinico \\ (AOUP) "Paolo Giaccone" of Palermo, Palermo, Italy.
}

\begin{abstract}
:
Background During the last few decades, several researches have been identified HPV genomic sequences in Head Neck Squamous Cell Carcinomas (HNSCC) and in Oral Potentially Malignant Disorders (OPMD) hypothesizing a possible viral etiological role. However, the reported prevalence of HPV-DNA (varying from $0 \%$ to $100 \%$ ) in these lesions result still very discordant.

Objective Human papillomavirus (HPV) infection in Oral Lichen Planus (OLP) has been largely investigated but not so extensively with respect to its morphological/histopathological features. The possible influence of hyper-keratosis/parakeratosis in HPV detection for keratotic variants of OLP is here proposed and investigated.

Materials and methods A total of 45 individuals with keratotic variants of OLP, clinically and histologically confirmed, were consecutively enrolled, before starting any treatment, and underwent oral brushing for HPV investigation. Viral DNA was extracted from oral brushed cells and HPV DNA researched by the combined use of the INNO-LiPA HPV Genotyping system (Innogenetics) and a PCR assay coupled with genome sequencing.

Results None of cytological samples collected resulted HPV-positive.

Conclusions In this preliminary study, oral HPV infection, investigated by means of a non-invasive oral sampling procedure and a standardized approach for HPV DNA detection, was not showed in any of the investigated cases. The presence of epithelial hyper-keratosis/parakeratosis in some variants of OLP could be a possible cause of impenetrability and/or difficult detection of the virus. Indeed, in case of keratotic variants of OLP, the possible potential false-negative results of HPV investigation by cytological procedure might be possible; on consequence, an alternative approach for viral detection (i.e. by histological sampling) should be considered.
\end{abstract}

Keywords: Human papillomavirus (HPV), Oral Lichen Planus (OLP), hyper keratosis/parakeratosis, oral cytobrush.

\section{INTRODUCTION}

Human Papillomaviridae are an heterogeneous group of epitheliotropic DNA viruses, extensively studied as a causative factor for high-grade cervical squamous dysplasia and cervical cancer. On the basis of the morphological similarities between oropharyngeal and genital epithelia, it may suggest that HPVs are more likely to play a role in the early stage of oral carcinogenesis [1] .

During the last few decades, several researches have been identified HPV genomic sequences in Head Neck Squamous Cell Carcinomas (HNSCC) and in Oral Potentially Malignant Disorders (OPMD) [2]. The reported prevalence of HPV-DNA (varying from $0 \%$ to 100\%) in these lesions result still very discordant probably due the perseverant extreme heterogeneity of investigating study methodology in terms of: i) different patient profiles, ii) the site of lesion, iii) diverse specimen types, iv) not uniform dissimilar methods of sampling storage; v) variable sensitivity of viral detection procedures and vi) 
intrinsic pathophysiology of the oral mucosa and lesions [2-4]. In relation to this latest aspect, the histological and clinical variability of OPMD and its implication with structural characteristics of HPV infection, has been little investigated.

Oral Lichen Planus (OLP) may occur in several clinical and histological varieties (e.g. reticular, plaque-type, atrophic, erosive-ulcerative and bullous variants) and hyperkeratosis and ortho-or parakeratosis are usually recognized as intrinsic elements of reticular and plaque-like OLP variants [5]. They represent a defensive response of oral epithelium to several environmental insults related to specific aetiopathogenetic mechanisms and could act as a barriers in respect of appropriate oral HPV sampling.

In the light of this consideration, the primary aim of this preliminary study was to investigate the prevalence of oral HPV infection in patients with keratotic variants of OLP utilizing oral cytobrush as sampling method and the INNOLiPA HPV Genotyping system in parallel with a nested $\mathrm{PCR} /$ sequencing assay as viral detection procedures.

\section{MATERIALS AND MeTHODS}

\section{Study Design}

From September 2013 to April 2015, 45 unselected immunocompetent adults [(F/M: 33/12, $\leq 50 />50$ years: 19/26] with keratotic variants of OLP, histologically confirmed, were consecutively enrolled at the Unit of Oral Medicine "V. Margiotta", University of Palermo, for HPV investigation by oral cytobrush. Topographic locations of the oral lesions included lip, gum, hard palate and tongue dorsum. Informed consent was obtained from all individual participants included in the study.

\section{HPV Collection and DNA Extraction}

Samples of oral mucosa cells were obtained by brushing (cytobrush: RAM, Mirandola, MO) from the site of the lesion; five complete backward and forward brushes were performed of each site. The brush was immediately squeezed on the side of a tube containing $5 \mathrm{~mL}$ of cold phosphate-buffered saline; cells were then centrifuged at $1600 \mathrm{rpm} \times 10 \mathrm{~min}$, washed with phosphate-buffered saline, centrifuged at $13000 \mathrm{rpm} \times 5 \mathrm{~min}$, and the pellet stored at $-20^{\circ} \mathrm{C}$. To extract total DNA, $200 \mu \mathrm{L}$ of digestion buffer containing $1 \mathrm{M}$ TrisHCl $(\mathrm{pH} 8.3$ ), 0.45\% Nonidet $\mathrm{P} 40,0.45 \%$ Tween 20, and $200 \mu \mathrm{g} / \mathrm{ml}$ proteinase $\mathrm{K}$ was added to each cellular pellet. Samples were then incubated at $60^{\circ} \mathrm{C}$ for 2 hours followed by incubation at $95^{\circ} \mathrm{C}$ for 10 minutes, to inactivate the proteinase $\mathrm{K}$ and stored at $20^{\circ} \mathrm{C}$ until used for DNA detection. A total of $10 \mu \mathrm{L}$ of the supernatant was checked for DNA quality by standard amplification of the human $\beta$-globin. Samples were checked for DNA quality by standard amplification of the human $\beta$-globin. HPV testing was performed by the INNO-LiPA HPV Genotyping Extra Amp kit (Innogenetics N.V., Ghent, Belgium), which allows detection of 28 mucosal HPV genotypes also in the presence of multiple type coinfections. Briefly, $10 \mu 1$ of each sample was amplified with biotinylated $\mathrm{SPF}_{10}$ primers, which amplify a 65-bp fragment of the L1 open reading frame and allow detection of at least 43 different HPV types. Thereafter, the amplicons were hybridized with 28 oligonucleotide probes, specific for $20 \mathrm{HR}$ - "High Risk" - genotypes $(16,18,26,31,33,35,39,45,51,52,53,56,58,59,66,68,69,70,73,82)$ and 8 LR - "Low Risk" - genotypes $(6,11,40,43,44,54,71,74)[6]$. In parallel, HPV DNA was also amplified in a nested PCR assay, by using the outer MY09/11 primer pair and the inner GP05+/06+ primers, as described elsewhere [7]. Three types of controls were included in each reaction series: blank control, HPV-negative cells Wi as negative control and HPV-18 DNA-positive HeLa cells, in dilutions from 20,000-50,000 down to 2-5 HPV-DNA copies, as positive control. Amplifications were carried out in a Mastercycler (Eppendorf, Hamburg, Germany) and the products analyzed in $8 \%$ polyacrylamide gel.

\section{ReSUlts}

The essential datum resulting from this investigation is the lack of detection of HPV-DNA in any oral samples collected.

\section{DiSCUSSION}

The hypothesis of a role for HPV in the multiphasic and multifactorial process of oral carcinogenesis has been exhaustively investigated but with a very wide range of viral prevalence reported. 
Excluding any ethno-geographical bias among the patient groups examined in literature, this wide range depends mainly on two variables: the site of the mucosa examined (oral cavity $v s$ oro-pharynx this last more susceptible to HPV penetration) [8] and sensitivity/specificity of HPV sampling and testing [2].

In reference to this last aspect, the impact of intrinsic pathophysiology of the oral mucosa - such as the hyperkeratosis/parakeratosis vs erosive/ulcerative patterns of oral lesions - on possible causes of altered HPV sampling has been poorly investigated.

The life cycle of HPV, the synthesis of viral DNA and the expression of viral genes are linked to the differentiation program of the keratinocytes [9]. Infection usually occurs through micro-wounds of the mucosal epithelium and, in order to activate infection, the virus must have access to basal and parabasal layers, where the specific $\alpha 6$ integrine receptor is present. Depending on the host immunological reaction, such process may spontaneously abort or progress. When the infection becomes productive, the integration of the HPV-DNA occurs and the viral genes expression sequentially proceeds following the epithelial squamous differentiation, going up to higher epithelial layers along with the formation of the complete virion [10]. The appropriate presence of cells from these layers is considered an important parameter in evaluation of specimen adequacy for HPV detection. On the contrary, the epithelial hyperkeratosis/parakeratosis could represent a significant barrier to the adequate sampling and generate false-negative screening results [11].

In the last 25 years, only 5 studies investigated HPV-DNA in OLP lesions clinically and/or histologically differentiated from other nonspecific OPMD and morphologically distinguished in keratotic and/or atrophic/erosive variants (Table1).

Table 1. Review of the studies on prevalence of HPV in different variants of OLP (1990-2015)

\begin{tabular}{|c|c|c|c|}
\hline Authors (year) & $\begin{array}{c}N O L P \\
\text { (variant) }\end{array}$ & $\%$ HPV (genotype) & $\begin{array}{c}\text { Method of sampling/HPV } \\
\text { detection }\end{array}$ \\
\hline Jontell et al ${ }^{[13]}(1990)$ & $20(\mathrm{E})$ & $\begin{array}{l}30 \%(11) \\
65 \%(11 / 6)\end{array}$ & $\begin{array}{l}\text { biopsy/SBH } \\
\text { biopsy/PCR }\end{array}$ \\
\hline Campisi et al ${ }^{[14]}(2004)$ & $\begin{array}{c}27 \text { (non } \\
\text { A/E) } \\
44(\mathrm{~A} / \mathrm{E})\end{array}$ & $\begin{array}{l}18.5 \%(18 / 16 / 31 / 6) \\
20.4 \%(18 / 16 / 31 / 6)\end{array}$ & $\begin{array}{l}\text { cytobrush/PCR } \\
\text { cytobrush/PCR }\end{array}$ \\
\hline Szarka et al ${ }^{[15]}(2009)$ & $\begin{array}{c}58 \text { (non } \\
\text { A/E) } \\
61(\mathrm{~A} / \mathrm{E})\end{array}$ & $\begin{array}{c}22.4 \%(6 / 11 / 16 / 18 / 33) \\
42.6 \%(6 / 11 / 32 / 55 / 16 / 18 / 33 / 39)\end{array}$ & $\begin{array}{l}\text { cytobrush/PCR } \\
\text { cytobrush/PCR }\end{array}$ \\
\hline Mattila et al ${ }^{[16]}(2012)$ & $82(\mathrm{~A})$ & $19 \%(6 / 11 / 16 / 31 / 33)$ & biopsy/PCR \\
\hline Arirachakaran et al ${ }^{[17]}(2013)$ & $\begin{array}{l}12(\mathrm{~K}) \\
23(\mathrm{~A}) \\
2(\mathrm{E} / \mathrm{U})\end{array}$ & $\begin{array}{c}0 \% \\
0 \% \\
50 \%(16) \\
\end{array}$ & $\begin{array}{l}\text { biopsy/PCR } \\
\text { biopsy/PCR } \\
\text { biopsy/PCR }\end{array}$ \\
\hline
\end{tabular}

N: number; OLP: Oral Lichen Planus; E: erosive, A: atrophic, K: Keratotic, U: Ulcerative; SBH: Southern Blot Hybridization, PCR: Polymerase Chain Reaction

Generally, in non-atrophic/erosive variants of OLP, the prevalence of HPV is lower than that detected in atrophic/erosive OLP, although with different statistical significance. A possible explanation may be that the atrophic/erosive tissue is characterized by increased permeability and, on consequence, more susceptible to both HPV penetration and/or viral DNA detection.

In previous study of Giovannelli et al, oral brushing was performed in 49 OLP without any morphological distinction. However, it was evident that HPV was significantly less likely (0.32 time) to be detected in lesions located in keratinized than in non-keratinized sites suggesting a possible protective role of the keratotic epithelial layer [12].

In our study, we selected only keratotic OLP, histologically confirmed and situated in keratinized mucosal sites, and we did not find HPV-DNA in any samples collected. This results was obtained despite the use of nested PCR/sequencing and INNOLiPA HPV/genotyping assay as viral detection procedures in order to minimize the possible role of low productivity of the HPV in the infected epithelium [18]. 
To the best of our knowledge, this is the first study using these selection criteria and hypothesizing the possible role of hyperkeratosis/parakeratosis in the cause of negative oral HPV tests.

In the only investigation with the same hypothesis, although in the gynaecological field, Xiao et al. found that these intrinsic pathophysiological cervical conditions, were significantly higher in the group with LSIL (Low-grade Squamous Intraepithelial Lesion biopsy) and negative Pap/HPV tests than in the group with LSIL and positive Pap/HPV tests, proposing a key role of hyperkeratosis in the possible false negative results of Pap/HPV tests [11].

Similarly we suppose that the presence of hyperkeratosis/parakeratosis in some varieties of OLP lesions could impair the adequate exfoliation cells in oral cytological samples resulting in falsenegative HPV-DNA detection.

In order to validate this suggestion, further researches with appropriate control groups (e.g. the same HPV detection in histological samples of keratotic variants of OLP) are necessary.

Original Publication: This work contains original unpublished work and is not being submitted for publication elsewhere at the same time

Ethical approval: All the procedures reported were approved by the Internal Ethical Committee of the University Hospital A.U.O.P "P. Giaccone" of Palermo (Internal registry: 11/2011) and were in accordance with the 1964 Helsinki declaration and its later amendments or comparable ethical standards. Informed consent was obtained from all individual participants included in the study.

Authorship: Vera Panzarella was responsable of the patient selection, study design, data analysis and interpretation. Giuseppina Capra had acquired and processed the microbiological data. Lucia Giovannelli was responsible for critical revision of the paper for important intellectual content. Giuseppina Campisi carried out the supervision of the study and approved the final version of the manuscript.

\section{REFERENCES}

[1] Gupta S. Role of human papillomavirus in oral squamous cell carcinoma and oral potentially malignant disorders: A review of the literature. Indian journal of dentistry 2015; 6: 91-98

[2] Syrjanen S, Lodi G, von Bultzingslowen I, Aliko A, Arduino P, Campisi G, Challacombe S, Ficarra G, Flaitz C, Zhou HM et al. Human papillomaviruses in oral carcinoma and oral potentially malignant disorders: a systematic review. Oral diseases 2011; 17 Suppl 1: 58-72

[3] Rautava J, Syrjanen S. Human papillomavirus infections in the oral mucosa. J Am Dent Assoc 2011; 142: 905-914

[4] Mighty KK, Laimins LA. The role of human papillomaviruses in oncogenesis. Recent results in cancer research. Fortschritte der Krebsforschung. Progres dans les recherches sur le cancer 2014; 193: 135-148

[5] Gupta S, Jawanda MK. Oral Lichen Planus: An Update on Etiology, Pathogenesis, Clinical Presentation, Diagnosis and Management. Indian journal of dermatology 2015; 60: 222-229

[6] Kleter B, van Doorn LJ, ter Schegget J, Schrauwen L, van Krimpen K, Burger M, ter Harmsel B, Quint W. Novel short-fragment PCR assay for highly sensitive broad-spectrum detection of anogenital human papillomaviruses. The American journal of pathology 1998; 153: 1731-1739.

[7] Ammatuna P, Giovannelli L, Giambelluca D, Mancuso S, Rubino E, Colletti P, Mazzola G, Belfiore P, Lima R. Presence of human papillomavirus and Epstein-Barr virus in the cervix of women infected with the human immunodeficiency virus. Journal of medical virology 2000; 62: 410-415

[8] Termine N, Panzarella V, Falaschini S, Russo A, Matranga D, Lo Muzio L, Campisi G. HPV in oral squamous cell carcinoma vs head and neck squamous cell carcinoma biopsies: a metaanalysis (1988-2007). Annals of oncology: official journal of the European Society for Medical Oncology / ESMO 2008; 19: 1681-1690

[9] Longworth MS, Laimins LA. Pathogenesis of human papillomaviruses in differentiating epithelia. Microbiology and molecular biology reviews: MMBR 2004; 68: 362-372

[10] Miller CS, Johnstone BM. Human papillomavirus as a risk factor for oral squamous cell carcinoma: a meta-analysis, 1982-1997. Oral surgery, oral medicine, oral pathology, oral radiology, and endodontics 2001; 91: 622-635 
[11] Xiao GQ, Emanuel PO. Cervical parakeratosis/hyperkeratosis as an important cause for false negative results of Pap smear and human papillomavirus test. The Australian \& New Zealand journal of obstetrics \& gynaecology 2009; 49: 302-306

[12] Giovannelli L, Campisi G, Colella G, Capra G, Di Liberto C, Caleca MP, Matranga D, D'Angelo M, Lo Muzio L, Ammatuna P. Brushing of oral mucosa for diagnosis of HPV infection in patients with potentially malignant and malignant oral lesions. Molecular diagnosis \& therapy 2006; 10: 49-55

[13] Jontell M, Watts S, Wallstrom M, Levin L, Sloberg K. Human papilloma virus in erosive oral lichen planus. Journal of oral pathology \& medicine: official publication of the International Association of Oral Pathologists and the American Academy of Oral Pathology 1990; 19: 273277

[14] Campisi G, Giovannelli L, Arico P, Lama A, Di Liberto C, Ammatuna P, D'Angelo M. HPV DNA in clinically different variants of oral leukoplakia and lichen planus. Oral surgery, oral medicine, oral pathology, oral radiology, and endodontics 2004; 98: 705-711

[15] Szarka K, Tar I, Feher E, Gall T, Kis A, Toth ED, Boda R, Marton I, Gergely L. Progressive increase of human papillomavirus carriage rates in potentially malignant and malignant oral disorders with increasing malignant potential. Oral microbiology and immunology 2009; 24: 314-318

[16] Mattila R, Rautava J, Syrjanen S. Human papillomavirus in oral atrophic lichen planus lesions. Oral oncology 2012; 48: 980-984

[17] Arirachakaran P, Chansaengroj J, Lurchachaiwong W, Kanjanabud P, Thongprasom K, Poovorawan Y. Oral lichen planus in thai patients has a low prevalence of human papillomavirus. ISRN dentistry 2013: 362750

[18] Watts SL, Brewer EE, Fry TL. Human papillomavirus DNA types in squamous cell carcinomas of the head and neck. Oral surgery, oral medicine, and oral pathology 1991; 71: 701-707 